Tanja Mališ

Diana Šimić Penava

https://doi.org/10.21278/TOF.41302

ISSN 1333-1124

eISSN 1849-1391

\title{
THE IMPACT OF LATERAL RESTRAINT ON STRUCTURAL STABILITY OF THIN-WALLED C-CROSS SECTION COLUMN SUBJECTED TO AXIAL FORCE
}

\begin{abstract}
Summary
The paper analyses the impact of lateral restraining by trapezoidal steel sheeting on the structural stability of thin-walled C-cross section columns subjected to axial forces. Firstly, mechanical properties of the column material (steel) and lateral stiffness of the rotational restraint are determined by testing standard specimens in a laboratory. Based on the obtained data, a stability analysis of unrestrained columns and of columns laterally restrained by trapezoidal steel sheeting has been carried out and critical forces have been determined analytically by using the theory of thin-walled beams, numerically by using the finite element method (FEM), and experimentally by testing the C-cross section columns in a laboratory. The analysis of critical forces and stability shows that the calculation according to the theory of thin-walled beams and the FEM calculation gives results similar to the results of the experimental tests. By comparing the results of the investigation into thin-walled C-cross section columns with and without lateral restraints a significant influence of lateral restraints on the stability of thin-walled C-cross sections subjected to axial forces has been proven: lateral restraint significantly affects final results of the level of the critical force, raising the possibility of optimizing the use of such structures in practice.
\end{abstract}

Key words: $\quad$ structural stability, critical force, C-cross section steel columns, lateral restraint, trapezoidal steel sheeting, axial loading, finite element method

\section{Introduction}

Thin-walled open section members (beams and columns) are elements of engineering structures, on which particular interest has been focused lately in the field of construction due to their property of efficiency. Production processes nowadays have evolved to the point that there are almost no limitations in the design of steel sheets and thin-walled profiles, which opens up various possibilities in the design of modern structures. Such profiles can now be used because of the development of modern design standards of thin-walled members, which are based on a probabilistic analysis of a large number of laboratory tests [1].

However, the behaviour of thin-walled profiles under load is much more complex than the behaviour of thin-walled closed section members and the behaviour of solid cross section members [2, 3]. In order to extend the theoretical and experimental knowledge of the 
complexity of behaviour of thin-walled open section members, this study pays special attention to the stability of laterally restrained thin-walled C-cross section members. Because of the complex shape of such members, their behaviour is also more complex at the same time, and their tendency towards the loss of structural stability is important. It should be noted that in the case of solid cross section members, structural instability mainly appears as flexural buckling, while in the case of thin-walled members there are flexural buckling, torsional buckling and flexural-torsional buckling, lateral form of loss of stability, and local loss of stability [4-9]. Because of that, in the design of thin-walled structures the possibility of an exact determination of the state of stability is of particular importance.

This paper includes a study of the stability of thin-walled C-cross section columns, unrestrained and laterally restrained by trapezoidal steel sheeting, subjected to axial forces. Several researchers have investigated the loss of stability of both unrestrained and laterally restrained thin-walled open cross section beams [10-16]. However, the scope of these investigations is limited to beams subjected to gravity or lifting load, and such kind of load is included in standards [17]. The issue of laterally restrained column subjected to axial force has been insufficiently addressed both in scientific research and the existing regulations [4]. The aim of this study is to determine the degree of influence of lateral restraint on the stability of thin-walled open section columns subjected to axial forces, thereby broadening the current knowledge about the behaviour of thin-walled open cross section members in the area of loss of stability. By comparing and analysing the results of the theoretical and the experimental investigation, the possibility of optimizing the use of thin-walled open cross section columns in practice through material savings and weight reduction of girders is tested.

\section{Review of elastic stability using the theory of thin-walled beams}

\subsection{Unrestrained beams}

It is assumed that an unrestrained flat thin-walled beam with an arbitrary cross section, Figure 1, is subjected to the compressive centric force $F$.

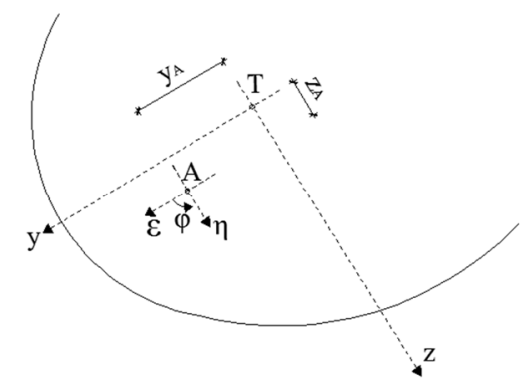

Fig. 1 Unrestrained thin-walled open cross section beam

The axes $y, z$ are the main inertia axes of the cross section, while the axis $x$ is a longitudinal axis of the beam. Point $A$ is the shear centre, and point $T$ the centre of gravity of the cross section. Displacement components of the shear centre $A$ in the direction of the main axes of inertia $y$ and $z$ are denoted by $\varepsilon(\mathrm{x})$ and $\eta(\mathrm{x})$, while $\varphi(\mathrm{x})$ is a rotation angle of the cross section around the axis of the shear centre. $y_{A}$ and $z_{A}$ are coordinates of the shear centre.

Equations of equilibrium for the beam which is subjected to the centric axial force $F$ after the loss of stability may be written in the following form [2, 3, 18]:

$$
\begin{aligned}
& E \cdot I_{z} \cdot \varepsilon^{I V}+F \cdot \varepsilon^{\prime \prime}+z_{A} \cdot F \cdot \varphi^{\prime \prime}=0 \\
& E \cdot I_{y} \cdot \eta^{I V}+F \cdot \eta^{\prime \prime}-y_{A} \cdot F \cdot \varphi^{\prime \prime}=0 \\
& E \cdot I_{\omega} \cdot \varphi^{I V}+\left(r^{2} \cdot F-G \cdot I_{t}\right) \cdot \varphi^{\prime \prime}+z_{A} \cdot F \cdot \varepsilon^{\prime \prime}-y_{A} \cdot F \cdot \eta^{\prime \prime}=0
\end{aligned}
$$


$E$ is the elasticity modulus and $G$ is the shear modulus. $I_{y}$ and $I_{z}$ are the main axial moments of inertia. $I_{t}$ is the torsional moment of inertia (Saint-Venant torsional constant). $I_{\omega}$ is the main sectorial moment of inertia of the cross section. $r^{2}$ is given in Eq. (2), where $A_{S}$ is the cross-sectional area.

$$
r^{2}=\frac{I_{y}+I_{z}}{A_{S}}+y_{A}^{2}+z_{A}^{2}
$$

The general solution to the system of Eq. (1) contains 12 constants of integration. In order to determine these constants, it is necessary to specify 12 boundary conditions. For homogeneous boundary conditions, a system of linear homogeneous equations is obtained. The critical load is determined from the condition that the determinant of the system is equal to zero. The beam with boundary conditions being fixed slide, with the span $l$, and subjected to the compressive centric force $F$ is considered, Fig. 2.

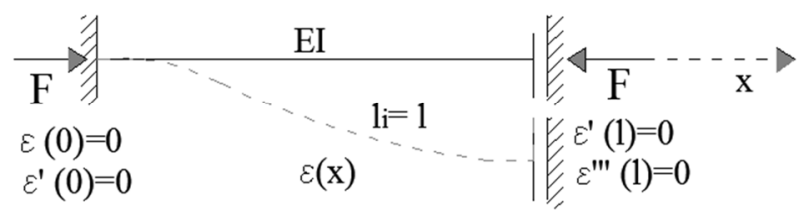

Fig. 2 The considered thin-walled beam with compressive centric force

For the fixed-slide beam shown in Fig. 2, the boundary conditions are:

$$
\begin{aligned}
& \text { for } x=0, \quad \varepsilon=\eta=\varphi=0, \quad \varepsilon^{\prime}=\eta^{\prime}=\varphi^{\prime}=0 \\
& \text { for } x=l, \quad \varepsilon^{\prime}=\eta^{\prime}=\varphi^{\prime}=0, \quad \varepsilon^{\prime \prime \prime}=\eta^{\prime \prime \prime}=\varphi^{\prime \prime \prime}=0
\end{aligned}
$$

For the given boundary conditions, the solution to Eq. (1) can be assumed as follows:

$$
\varepsilon=C_{1} \cdot\left(1-\cos \frac{n \cdot \pi}{l} \cdot x\right), \quad \eta=C_{2} \cdot\left(1-\cos \frac{n \cdot \pi}{l} \cdot x\right), \quad \varphi=C_{3} \cdot\left(1-\cos \frac{n \cdot \pi}{l} \cdot x\right)
$$

where $C_{1}, C_{2}$ and $C_{3}$ are unknown constants, and $n$ is the whole positive number of sine half waves along the length of the beam. Once we put the expression (4) into Eq. (1) we get:

$$
\left(\begin{array}{ccc}
n^{2} \cdot \frac{\pi^{2} \cdot E \cdot I_{z}}{l^{2}}-F & 0 & -z_{A} \cdot F \\
0 & n^{2} \cdot \frac{\pi^{2} \cdot E \cdot I_{y}}{l^{2}}-F & y_{A} \cdot F \\
-z_{A} \cdot F & y_{A} \cdot F & n^{2} \cdot \frac{\pi^{2} \cdot E \cdot I_{\omega}}{l^{2}}+G \cdot I_{t}-r^{2} \cdot F
\end{array}\right) \cdot\left\{\begin{array}{l}
C_{1} \\
C_{2} \\
C_{3}
\end{array}\right\}=0
$$

For the system of Eq. (5) to have a solution different from a trivial one, the determinant of the system must be equal to zero:

$$
\left|\begin{array}{ccc}
F_{z}-F & 0 & -z_{A} \cdot F \\
0 & F_{y}-F & y_{A} \cdot F \\
-z_{A} \cdot F & y_{A} \cdot F & r^{2} \cdot\left(F_{\omega}-F\right)
\end{array}\right|=0
$$

The Euler critical buckling forces in the main planes (pure flexural buckling) $F_{z}, F_{y}$ are shown in the expression (7):

$$
F_{z}=n^{2} \cdot \frac{\pi^{2} \cdot E \cdot I_{z}}{l^{2}}, \quad F_{y}=n^{2} \cdot \frac{\pi^{2} \cdot E \cdot I_{y}}{l^{2}}
$$


The critical force for the torsional instability (pure torsional buckling) $F_{\omega}$ is shown in expression (8):

$$
F_{\omega}=\frac{1}{r^{2}} \cdot\left(n^{2} \cdot \frac{\pi^{2} \cdot E \cdot I_{\omega}}{l^{2}}+G \cdot I_{t}\right)
$$

Since the matrix of the system (5) is a symmetrical one, the determinant of the system (6) has three real and positive roots: $F_{1}, F_{2}, F_{3}$. For each of the three roots, the elastic line consists of $n$ sine half waves. Of practical importance is only the case when the elastic line consists of a single sine half wave, which, according to expressions (4), (7) and (8) for $n=1$, gives:

$$
\begin{aligned}
& F_{z}=\frac{\pi^{2} \cdot E \cdot I_{z}}{l^{2}}, \quad F_{y}=\frac{\pi^{2} \cdot E \cdot I_{y}}{l^{2}} \\
& F_{\omega}=\frac{1}{r^{2}} \cdot\left(\frac{\pi^{2} \cdot E \cdot I_{\omega}}{l^{2}}+G \cdot I_{t}\right) \\
& \text { for: } F_{z}<F_{y}<F_{\omega} \quad \text { it will be } F_{1} \leq F_{z} \leq F_{2} \leq F_{y} \leq F_{\omega} \leq F_{3} \\
& \text { for: } F_{\omega}<F_{z}<F_{y} \text { it will be } F_{1} \leq F_{\omega} \leq F_{z} \leq F_{2} \leq F_{y} \leq F_{3} .
\end{aligned}
$$

The critical buckling force of a beam is relevant as follows:

$$
F_{k r}=F_{\text {min }}=F_{1}
$$

and it suits both buckling and twisting of a beam if it is less than $F_{y}, F_{z}, F_{\omega}$; pure flexural buckling if it is equal to $F_{z}$ (or $F_{y}$ ); pure torsional buckling if it is equal to $F_{\omega}$.

In the cases when the beam is supported in some other way, regarding the analogy with the problems of stability of a flat beam with a solid cross section, the expressions for critical compressive forces can be summarized in the following form [3]:

$$
\begin{aligned}
& F_{z}=\frac{\pi^{2} \cdot E \cdot I_{z}}{(\mu \cdot l)^{2}}, \quad F_{y}=\frac{\pi^{2} \cdot E \cdot I_{y}}{(\mu \cdot l)^{2}} \\
& F_{\omega}=\frac{1}{r^{2}} \cdot\left(\frac{\pi^{2} \cdot E \cdot I_{\omega}}{(\psi \cdot l)^{2}}+G \cdot I_{t}\right)
\end{aligned}
$$

In Eq. (11) different coefficients of the effective length $\mu$ and $\psi$ are introduced, as the boundary conditions for deflection and rotation in the end sections of the beam do not have to be identical. For a beam which is at one end fixed and at the other freely supported, the coefficient of the effective length of the beam by bending is $\mu=0.7$, and the ratio of the effective length of the beam to the loss of stability by twisting is $\psi=0.7$. For a beam which is freely supported at both ends, $\mu=\psi=1.0$, for a beam which is fixed at both ends, $\mu=\psi=0.5$, for a beam fixed at one end and free at the other, $\mu=\psi=2.0$. The member $\mu l$ represents the length of flexural buckling of the beam $l_{i}=\mu l$, and the member $v l$ the length of torsional buckling of the beam $l_{T}=\psi l$. In our case $\mu=\psi=1.0, l_{i}=l_{T}=l$ applies, Fig. 2.

\subsection{Laterally restrained beams}

It is assumed that a laterally restrained flat thin-walled beam with an arbitrary cross section is subjected to the compressive centric force $F$, Fig. 3 . The beam is laterally restrained by a transverse rigid connection in the horizontal direction and by a rotational elastic connection, which is a way of modelling beams laterally restrained by trapezoidal steel sheeting with sufficient stiffness according to Eurocode 3 [17]. Since we assume that the trapezoidal steel sheeting is directed horizontally (direction $y_{1}$ ), there are no lateral restraints in the vertical direction (direction $z_{1}$ ) because the resistance to displacement in that direction is negligible. 
In Fig. 3, the axes $y, z$ are the main inertia axes of the cross section, while the axis $x$ is a longitudinal axis of the beam. Point $A$ is the shear centre, point $T$ the centre of gravity of the cross section, and point $H$ the point of lateral restraint. Displacement components of the shear centre $A$ in the direction of the main axes of inertia $y$ and $z$ are denoted by $\varepsilon(\mathrm{x})$ and $\eta(\mathrm{x})$, while $\varphi(\mathrm{x})$ is a rotation angle of the cross section around the axis of the shear centre. $y_{A}$ and $z_{A}$ are the coordinates of the shear centre, and $y_{H}$ and $z_{H}$ are the coordinates of the point of lateral restraint. Axes $y_{1}$ and $z_{1}$ are the axes oriented in the direction of the lateral restraint and perpendicular to it, and $\alpha$ represents the angle of the major axis of inertia $y$ relative to the axis $y_{1}$.

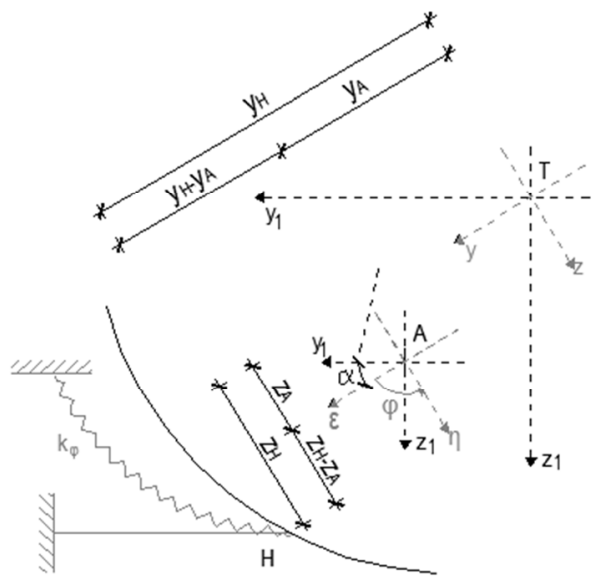

Fig. 3 Laterally restrained thin-walled open cross section beam

Coefficient $k_{\varphi}$ has dimension moment/length and represents the moment acting on the unit length of the beam for corresponding unit rotation angle of the line element between two infinitely close points [2].

The displacement components of the point $H$ in the direction of the main axes of inertia $y$ and $z$ are:

$$
\begin{aligned}
& \varepsilon_{H}=\varepsilon-\left(z_{H}-z_{A}\right) \varphi, \quad \eta_{H}=\eta+\left(y_{H}-y_{A}\right) \varphi \\
& \varphi_{H}=\varphi
\end{aligned}
$$

We assume that the displacement of the point $H$ in the direction of the rigid connection (horizontal direction) is equal to zero:

$$
0=\varepsilon_{H} \cos \alpha-\eta_{H} \sin \alpha
$$

According to Eq. (12a) and Eq. (13) we get:

$$
\varepsilon=\eta \cdot \operatorname{tg} \alpha+\left[\left(z_{H}-z_{A}\right)+\left(y_{H}-y_{A}\right) \operatorname{tg} \alpha\right] \varphi
$$

Equations of equilibrium of the laterally restrained thin-walled open section beam which is subjected to the centric axial force $F$ after the loss of stability are obtained by adding the reactive forces and the reactive moment from the lateral restraining $\overline{q_{y}}, \overline{q_{z}}, \bar{m}$ in the system of Eq. (1) [2]:

$$
\begin{aligned}
& E \cdot I_{z} \cdot \varepsilon^{I V}+F \cdot \varepsilon^{\prime \prime}+z_{A} \cdot F \cdot \varphi^{\prime \prime}-\overline{q_{y}}=0 \\
& E \cdot I_{y} \cdot \eta^{I V}+F \cdot \eta^{\prime \prime}-y_{A} \cdot F \cdot \varphi^{\prime \prime}-\overline{q_{z}}=0 \\
& E \cdot I_{\omega} \cdot \varphi^{I V}+\left(r^{2} \cdot F-G \cdot I_{t}\right) \cdot \varphi^{\prime \prime}+z_{A} \cdot F \cdot \varepsilon^{\prime \prime}-y_{A} \cdot F \cdot \eta^{\prime \prime}-\bar{m}=0
\end{aligned}
$$


The reactive forces and the reactive moment from the lateral restraining $\overline{q_{y}}, \overline{q_{z}}, \bar{m}$ in the direction of the main axes of inertia $y$ and $z$ may be written as follows:

$$
\begin{aligned}
& \overline{q_{y}}=\overline{q_{H}} \cos \alpha \\
& \overline{q_{z}}=-\overline{q_{H}} \sin \alpha \\
& \bar{m}=\left(y_{H}-y_{A}\right) \overline{q_{z}}-\left(z_{H}-z_{A}\right) \overline{q_{y}}-k_{\varphi} \varphi
\end{aligned}
$$

where $\overline{q_{H}}$ is the reactive force from the transverse rigid connection in the horizontal direction.

According to Eqs. (14), (15) and (16) a system of Eq. (17) is obtained, which represents equations of equilibrium of the beam laterally restrained by a transverse rigid connection in the horizontal direction and by a rotational elastic connection subjected to the centric axial force $F$, after the loss of stability occurred $[2,3]$ :

$$
\begin{aligned}
& \left(E I_{y}+\operatorname{tg}^{2} \alpha E I_{z}\right) \eta^{I V}+F\left(1+\operatorname{tg}^{2} \alpha\right) \eta^{I I}+E I_{z} \operatorname{tg} \alpha\left[\left(z_{H}-z_{A}\right)+\left(y_{H}-y_{A}\right) \operatorname{tg} \alpha\right] \varphi^{I V}+ \\
& +\left[-y_{A}+z_{H} \operatorname{tg} \alpha+\operatorname{tg}^{2} \alpha\left(y_{H}-y_{A}\right)\right] F \varphi^{I I}=0 \\
& {\left[\operatorname{tg} \alpha\left(z_{H}-z_{A}\right)+\operatorname{tg}^{2} \alpha\left(y_{H}-y_{A}\right)\right] E I_{z} \eta^{I V}+\left[-y_{A}+z_{H} \operatorname{tg} \alpha+\left(y_{H}-y_{A}\right) \operatorname{tg}^{2} \alpha\right] F \eta^{I I}+} \\
& +E I_{\omega} \varphi^{I V}+\left[\left(z_{H}-z_{A}\right)+\left(y_{H}-y_{A}\right) \operatorname{tg} \alpha\right]^{2} E I_{z} \varphi^{I V}+\left\{r^{2} F-G I_{t}+F\left[\left(y_{H}-y_{A}\right)^{2} \operatorname{tg}^{2} \alpha+\right.\right. \\
& \left.\left.+\left(z_{H}-z_{A}\right)^{2}+2 \operatorname{tg} \alpha z_{H}\left(y_{H}-y_{A}\right)\right]\right\} \varphi^{I I}+k_{\varphi} \varphi=0
\end{aligned}
$$

For the given boundary conditions, if the buckling length $l_{i}=l_{T}$, for $n=1$, the solution to the system of Eq. (17) can be written in the form of the system of Eq. (18). The beam with the boundary conditions fixed-slide, with the span $l$, and subjected to the compressive centric force $F$ is considered, Fig. 2, so in our case $l_{i}=l_{T}=l$ applies.

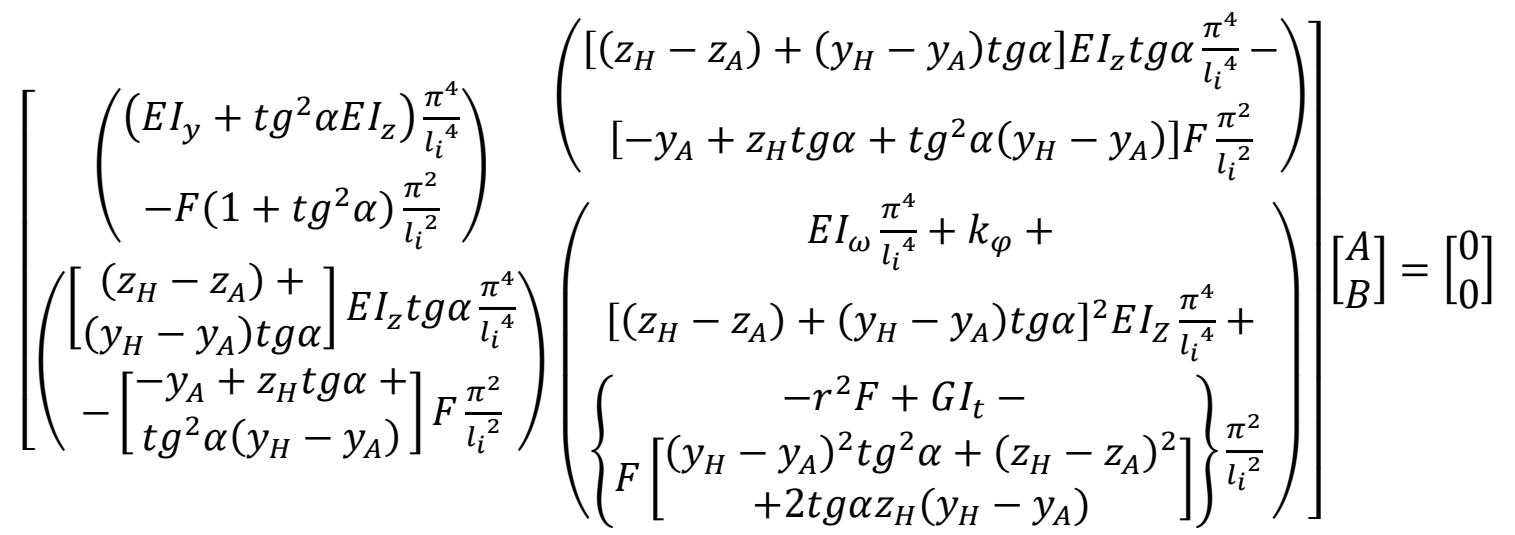

For the system of Eq. (18) to have a solution different from a trivial one, the determinant of the system must be equal to zero. Since the matrix of the system of Eq. (18) is symmetrical, the determinant of the system has two real and positive roots: $F_{1}$ and $F_{2}$. The critical buckling force of a beam $F_{k r}=F_{\min }=F_{1}<F_{2}$ is relevant, which in the general case suits both the buckling and the twisting of a beam.

\section{Determination of the critical force and form of loss of stability}

A calculation and analysis of stability of the steel thin-walled C-cross section column $(80 / 40 / 20 / 3 \mathrm{~mm})$, Fig. 4a, without lateral restraint and laterally restrained by trapezoidal steel sheeting ( $T$ 40/245/1 mm), Fig. 4b, is carried out:

- experimentally, by testing the models in a laboratory [17], 
- analytically, according to the theory of thin-walled open cross section beams $[2,3]$,

- numerically, by using the FEM with the SAP2000 v14 software (,buckling“" analysis) [19].

The columns with the span $l=170 \mathrm{~cm}$ are fixed at one end, slide at the other end, and loaded with compressive force in the centre of gravity of the cross section, Fig. 2.

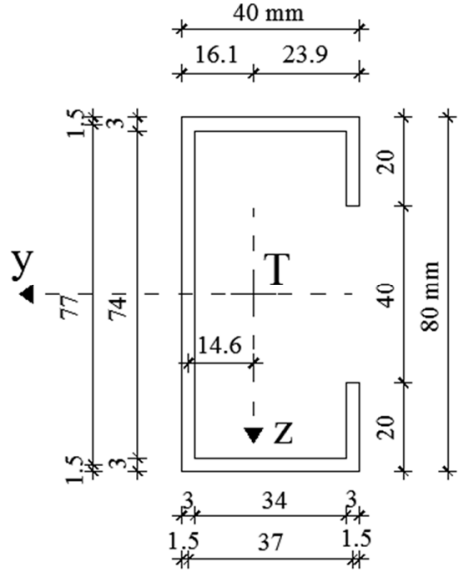

a)

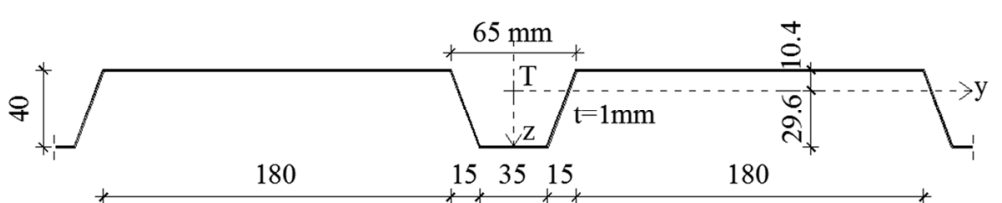

b)

Fig. 4 Tested profiles: a) thin-walled C-cross section column b) trapezoidal steel sheeting (lateral restraint)

\subsection{Experimental determination of the critical force}

Mechanical properties of steel from which the thin-walled C-cross section columns and trapezoidal sheeting are made are determined in a laboratory by testing a series of five standard specimens of columns and five standard specimens of sheeting using resistance strain gauges. The specimens were prepared according to HRN EN ISO 6892-1:2010. The obtained values of the mechanical properties of steel of which $\mathrm{C}$-cross section columns are made are: tensile strength $\sigma_{M}=416 \mathrm{MPa}$, yield stress $\sigma_{T}=306 \mathrm{MPa}$, proportional limit $\sigma_{T}=283 \mathrm{MPa}$, modulus of elasticity $E=203.8 \mathrm{GPa}$, Poisson's ratio $v=0.285$ and shear modulus $G=79.300 \mathrm{GPa}$. The obtained values of the mechanical properties of the trapezoidal steel sheeting are: tensile strength $\sigma_{M}=408 \mathrm{MPa}$, yield stress $\sigma_{T}=350 \mathrm{MPa}$, proportional limit $\sigma_{T}=275 \mathrm{MPa}$, modulus of elasticity $E=194.2 \mathrm{GPa}$, Poisson's ratio $v=0.300$ and shear modulus $G=74.692 \mathrm{GPa}$.

Torsional restraint achieved by adequately fastened sheeting perpendicular to the span of the column is determined according to EN 1993-1-3:2006+AC:2009 [17], combining laboratory testing with analytical calculation. Rotational stiffness of the rotation spring $C_{D}$ comprises the rotational stiffness of the sheeting and the beam connection $C_{D, A}$, and the rotational stiffness corresponding to the stiffness of the trapezoidal sheeting to the bending $C_{D, C}$, Eq. (19) $[2,3]$.

$$
C_{D}=\frac{1}{\frac{1}{C_{D, A}}+\frac{1}{C_{D, C}}}
$$

Rotational stiffness of the sheeting and the beam connection $C_{D, A}$ is determined by laboratory testing, during which four inductive strain gauges were set on an unrestrained flange of thin-walled C-cross section columns to measure the lateral displacement, Fig. 5. According to Annex A of EN 1993-1-3:2006+AC:2009, the force for which the lateral displacement $\delta$ of the unrestrained flange in the direction of loading is equal to one tenth of the web of column $h_{w} / 10$ should be found, which is in our case: $h_{w}=80 \mathrm{~mm} \rightarrow \delta=8 \mathrm{~mm}$. The obtained corresponding rotational stiffness of the sheeting and the beam connection is $C_{D, A}=0,91 \mathrm{kNm} / \mathrm{m}$. 

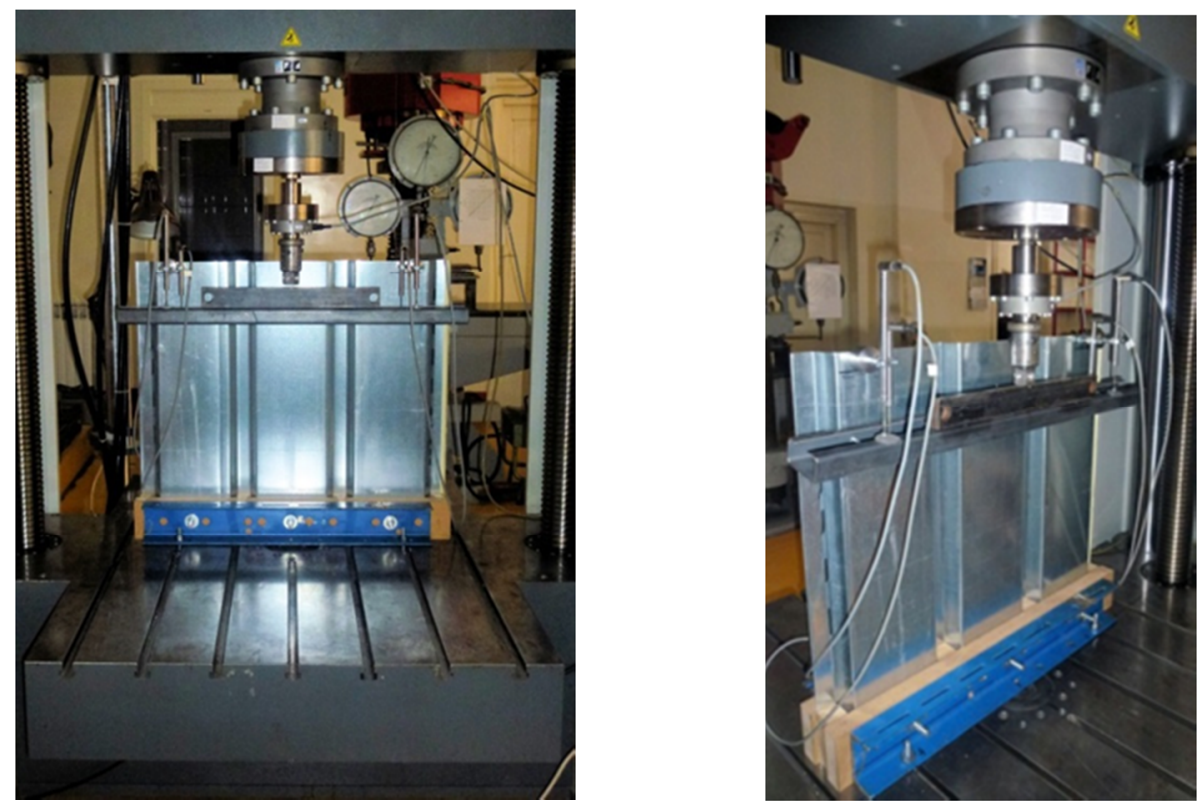

Fig. 5 Determination of rotational stiffness of the rotation spring

The rotational stiffness corresponding to the stiffness of the trapezoidal sheeting to the bending $C_{D, C}$ is determined by the analytical calculation. According to EN 1993-13:2006+AC:2009, for fixed-pinned steel sheeting the following applies:

$$
C_{D, C}=\frac{3 E I_{e f f}}{s}
$$

$s$ is the space between the thin-walled C-cross section column at one side and the fixed connection at the other side: $s=700 \mathrm{~mm}$, and $I_{\text {eff }}$ is the moment of inertia of the effective cross section, the position on which in our case the wider flange of sheeting is the compression flange: $I_{\text {eff }}=19,79 \mathrm{~cm}^{4} / \mathrm{m}$. The obtained rotational stiffness corresponding to the stiffness of the trapezoidal sheeting to the bending according to Eq. (20) equals $C_{D, C}=$ $164,54 \mathrm{kNm} / \mathrm{m}$, and the obtained total rotational stiffness of the rotation spring $C_{D}$ according to Eq. (19) equals $C_{D}=k_{\varphi}=0.9 \mathrm{kNm} / \mathrm{m}$.

Stability of the thin-walled C-cross section columns is tested in a static press. On the base of the columns a plate $200 / 200 / 30 \mathrm{~mm}$ in dimension is welded and connected to a plate $720 / 420 / 8 \mathrm{~mm}$ in dimension, which is connected to the ground, simulating the fixed boundary condition. On top of the columns a plate $120 / 120 / 10 \mathrm{~mm}$ in dimension is welded, sliding to a plate $120 / 120 / 30 \mathrm{~mm}$ in dimension, through which the compressive forces were acting, simulating the sliding boundary condition, Fig. 2. The steel plates and the columns are made of the same material exhibiting the same mechanical properties.

During testing in the laboratory inductive strain gauges (labels I1 - I13 for the unrestrained C-cross section column and labels I1-I8 for the laterally restrained C-cross section column) were placed on the thin-walled C-cross section columns to measure the lateral displacement and the resistance strain gauges (labels T1, T2) were placed to measure the longitudinal strain in the columns. The disposition of the measurement points on the Ccross section column is shown in Fig. 6.

Fig. 7a shows a thin-walled unrestrained C-cross section column and Fig. $7 \mathrm{~b}$ shows a thin-walled laterally restrained C-cross section column, both prepared for testing. The columns were gradually loaded with the increasing force $\Delta F=30 \mathrm{kN}$ until the loss of stability occurred. 
Structural Stability of Thin-Walled C-cross Section

Column Subjected to Axial Force
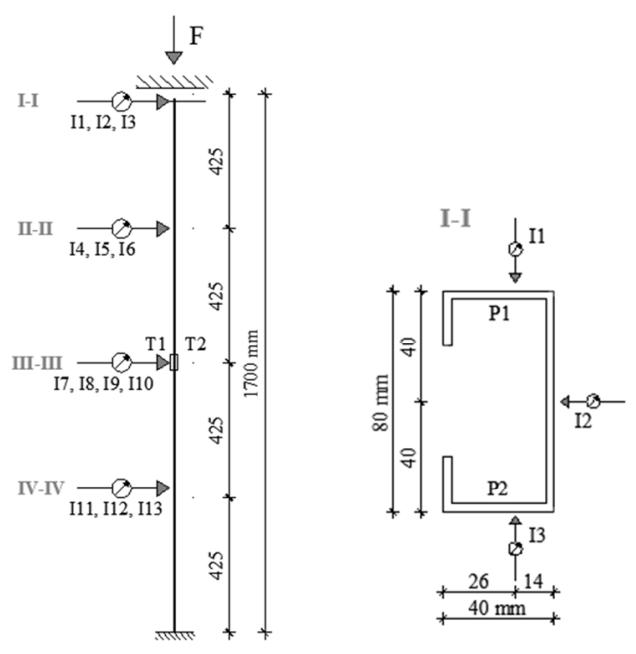

I-I
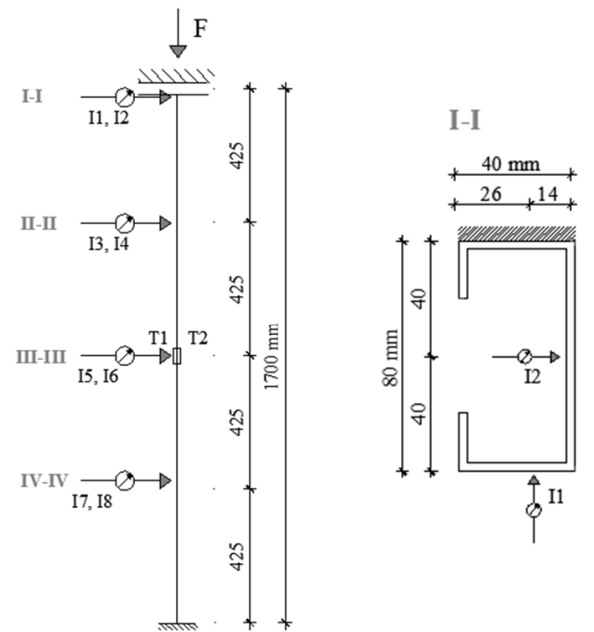
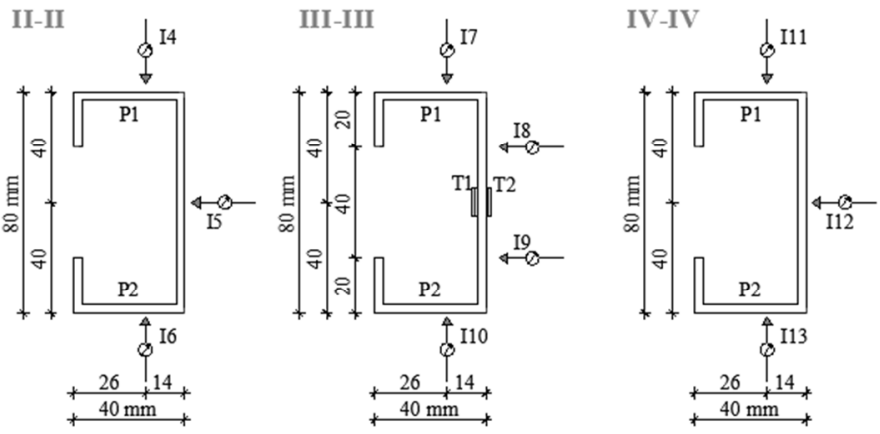

a)

II-II

III-III

IV-IV
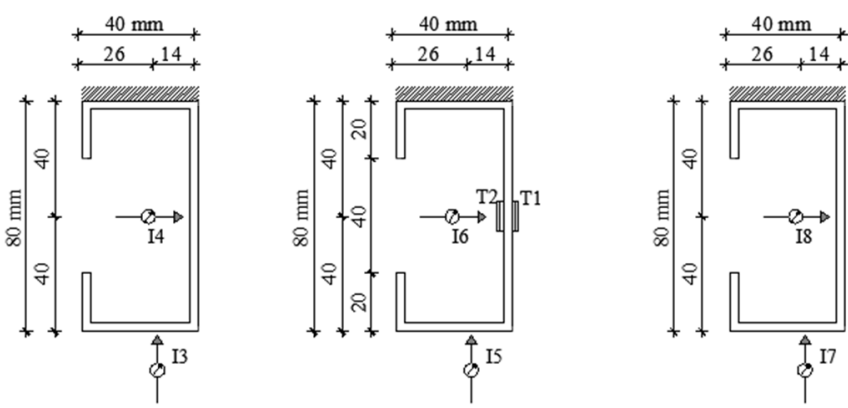

b)

Fig. 6 Disposition of measurement points: a) unrestrained column b) laterally restrained column

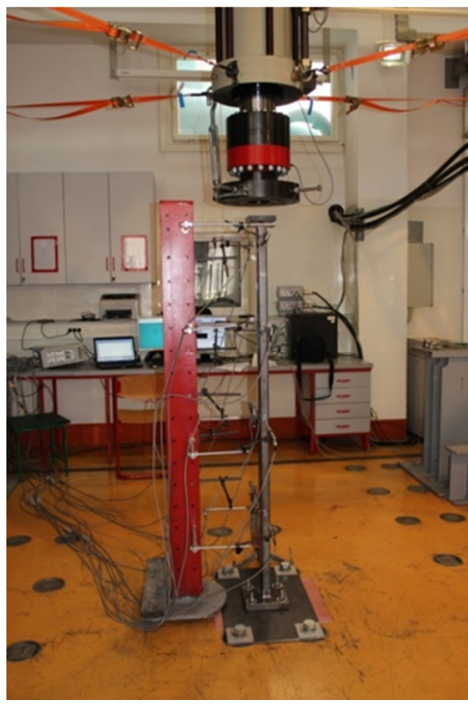

a)

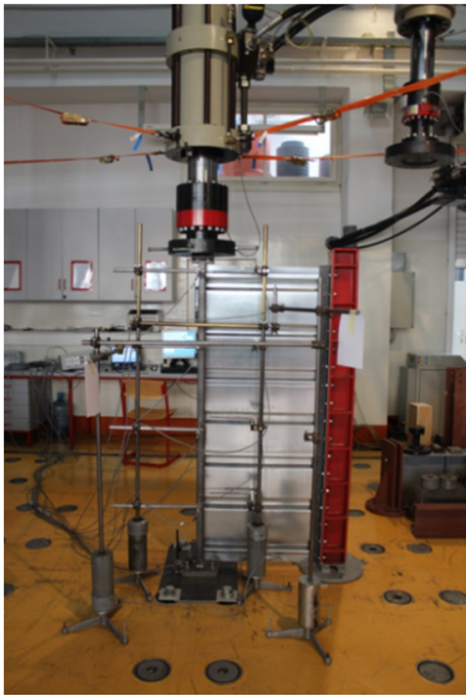

b)

Fig. 7 Models prepared for testing: a) unrestrained column b) laterally restrained column 
The loss of stability of the unrestrained thin-walled C-cross section column appeared under the global critical force $F_{k r}=90.00 \mathrm{kN}$ due to pure flexural in-plane buckling, Fig. 8 . Fig. 8a shows the form of loss of stability. Fig. $8 \mathrm{~b}$ shows the strain-stress diagram in section III-III measured with the resistance strain gauges T1 and T2. In Fig. 8c the height of columnmaximum displacements in phases diagram is shown, measured with the inductive strain gauges I2, I5, I8, I9, I12 for the web, I1, I4, I7, I1 1 for the flange P1 and I3, I6, I10, I13 for the flange P2, Fig. 6a. Stretching of the inductive strain gauges is shown as negative displacement, and shrinking as positive displacement. The increase in displacement when achieving the force of $90 \mathrm{kN}$ (phase 3 ) is not proportional to the increase in force as the model loses stability. The model was loaded once again, phase 4 , but again it could not withstand a force greater than the global critical force of $90 \mathrm{kN}$.

The loss of stability of the laterally restrained thin-walled C-cross section column appeared under the global critical force $F \mathrm{kr}=138.00 \mathrm{kN}$ due to simultaneous twisting and lateral out-plane bending, Fig. 9. Fig. 9a shows the form of loss of stability. Fig. 9b shows the strain-stress diagram in section III-III measured with the resistance strain gauges T1 and T2. In Fig. 9c, the height of column-maximum displacements in phases diagram is shown, measured with the inductive strain gauges I2, I4, I6, I8 for the web and I1, I3, I5, I7 for the unrestrained flange, Fig. 6b. Stretching of the inductive strain gauges is shown as negative displacement, and shrinking as positive displacement.

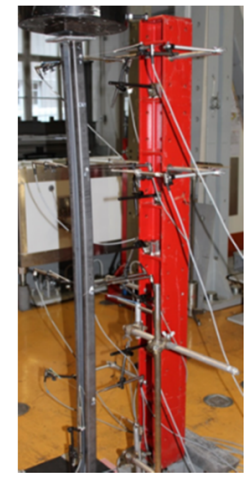

a)

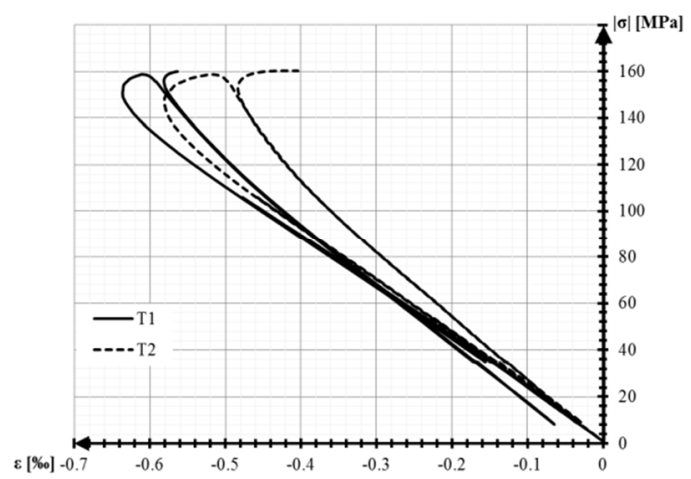

b)

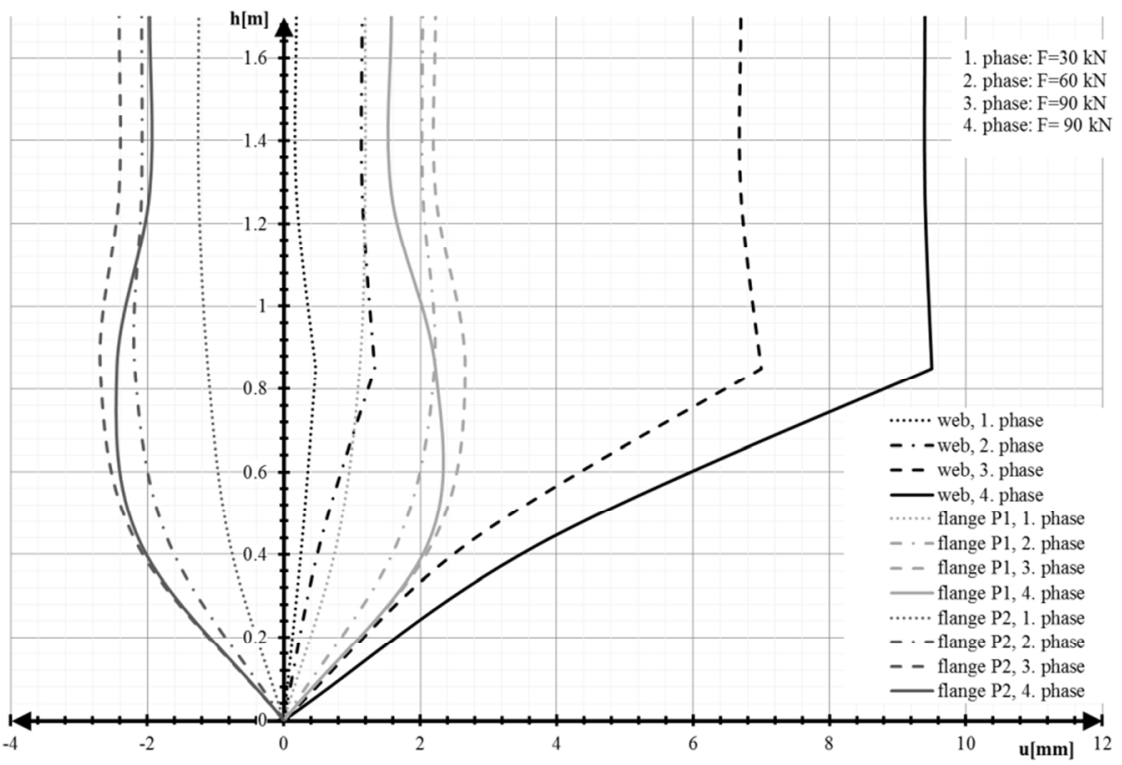

c)

Fig. 8 Loss of stability of the unrestrained thin-walled C-cross section column: a) form of loss of stability, b) strain-stress diagram, c) height-displacement diagram in phases 


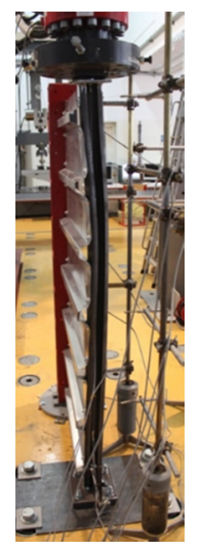

a)

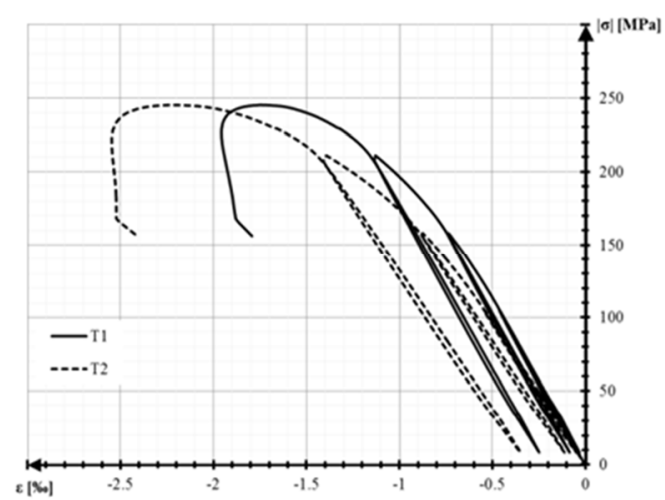

b)

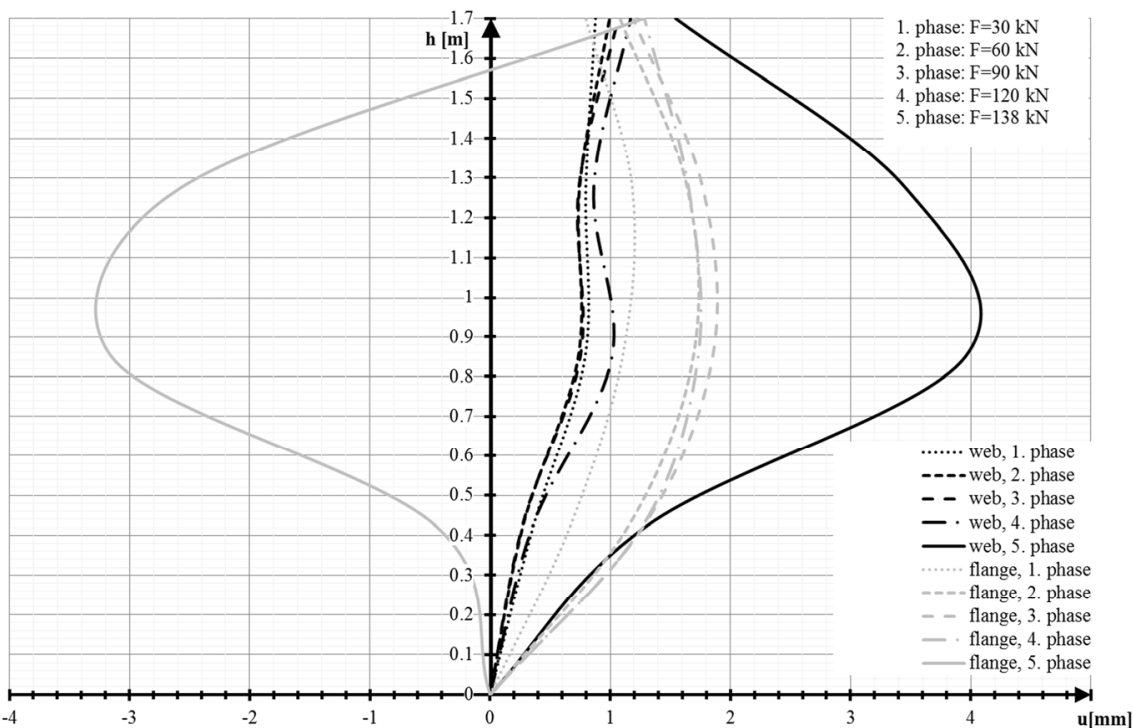

c)

Fig. 9 Loss of stability of the laterally restrained thin-walled C-cross section column: a) form of loss of stability, b) strain-stress diagram, c) height-displacement diagram in phases

\subsection{Analytical determination of the critical force}

The values of critical forces are determined analytically, based on the theory of thinwalled open cross section beams.

For the thin walled C-cross section $80 / 40 / 20 / 3$ column, the cross-sectional area is $S=564 \mathrm{~mm}^{2}$, Fig. 4 . The main moments of inertia of the cross section are: $I_{y}=541492.5 \mathrm{~mm}^{4}$; $I_{z}=133894.9 \mathrm{~mm}^{4}$. The torsional moment of inertia of the cross section is $I_{t}=1692 \mathrm{~mm}^{4}$. The main sectorial moment of inertia of the cross section is $I_{\omega}=247804125.8 \mathrm{~mm}^{6} . \mathrm{r}^{2}=2507.9$ $\mathrm{mm}^{2} ; y_{A}=36.2 \mathrm{~mm} ; z_{A}=0 . E=203.8 \mathrm{GPa}, G=79.3 \mathrm{GPa}, \sigma_{P}=283.0 \mathrm{MPa}, k_{\varphi}=0.9 \mathrm{kNm} / \mathrm{m}, \mu=$ $\psi=1.0, l_{i}=l_{T}=l=1.7 \mathrm{~m}$.

\subsubsection{Unrestrained columns}

Since the C-cross section has one axis of symmetry, because the major axis of inertia $y$ is at the same time the axis of symmetry of the cross section, $z_{A}=0$, that indicates that the determinant (6) of the system of Eq. (5) takes the following form:

$$
\left|\begin{array}{ccc}
F_{z}-F & 0 & 0 \\
0 & F_{y}-F & y_{A} \cdot F \\
0 & y_{A} \cdot F & r^{2} \cdot\left(F_{\omega}-F\right)
\end{array}\right|=0
$$


Using Eq. (11), the following values are obtained:

$F_{y}=376.9 \mathrm{kN} ; F_{z}=92.8 \mathrm{kN} ; F_{\omega}=122.3 \mathrm{kN}$.

By solving the determinant (21), three values of the critical force are obtained:

$$
\begin{gathered}
F_{k r}=\min \left\{F_{i}=\frac{r^{2}}{r^{2}-y_{A}^{2}}\left(\frac{F_{y}+F_{\omega}}{2} \pm \sqrt{\left.\left(\frac{F_{y}+F_{\omega}}{2}\right)^{2}-F_{y} F_{\omega} \frac{r^{2}-y_{A}^{2}}{r^{2}}\right)}\right\}=\right. \\
\min \left\{\begin{array}{c}
92.8 k N=F_{1} \\
102.4 k N=F_{2} \\
943.1 k N=F_{3}
\end{array}\right\}
\end{gathered}
$$

The critical buckling force of a column (10) $F_{k r}=F_{\text {min }}=F_{1}=F_{z}=92.8 \mathrm{kN}$ is relevant, which corresponds to the loss of the column's stability under pure flexural in-plane buckling.

The critical stress in the column at the time of the loss of stability is less than the proportional limit:

$$
\sigma_{k r}=\frac{F_{k r}}{A}=\frac{92800 \mathrm{~N}}{564 \mathrm{~mm}^{2}}=164.5 \mathrm{MPa}<\sigma_{P}=283.0 \mathrm{MPa} .
$$

Buckling occurs in the elastic area so the resulting critical force is relevant.

\subsubsection{Laterally restrained columns}

Since the C-cross section has one axis of symmetry, because the major axis of inertia $y$ is at the same time the axis of symmetry of the cross section, $z_{A}=0$, and since the angle $\alpha=0$, that indicates that the determinant of the system of Eq. (18) takes the following form:

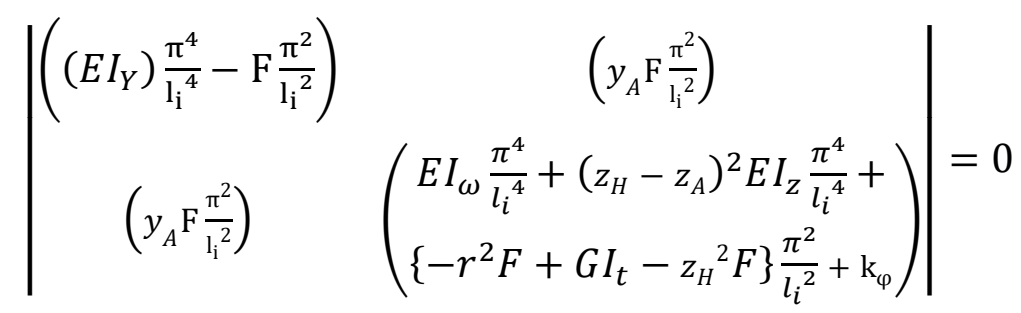

By solving the determinant (22), three values of the critical force are obtained:

$$
F_{1}=145.4 k N ; F_{2}=662.4 k N \text {. }
$$

The critical buckling force of a column (10) $F_{k r}=F_{\min }=F_{1}$ is relevant, which corresponds to the loss of the column's stability under simultaneous twisting and lateral outplane bending.

The critical stress in the column at the time of the loss of stability is less than the proportional limit:

$$
\sigma_{k r}=\frac{F_{k r}}{A}=\frac{145400 \mathrm{~N}}{564 \mathrm{~mm}^{2}}=257.8 \mathrm{MPa}<\sigma_{P}=283.0 \mathrm{MPa} .
$$

Buckling occurs in the elastic area so the resulting critical force is relevant. 


\subsubsection{Numerical determination of the critical force}

The calculation of the thin-walled C-cross section $80 / 40 / 20 / 3 \mathrm{~mm}$ column that is 1700 $m m$ high, unrestrained and laterally restrained by the trapezoidal steel sheeting $T 40 / 245$ / $1 \mathrm{~mm}, k_{\varphi}=0.9 \mathrm{kNm} / \mathrm{m}$, is carried out using a finite element method in the SAP2000 v14 software [19]. The thin-walled columns are modelled by plate elements: they are divided into 2800 rectangular finite elements, $10 / 12 / 14 \mathrm{~mm}$ in dimension and $3 \mathrm{~mm}$ thick. The columns are modelled using the mechanical properties and boundary conditions equal to those used in the experimental and analytical study. It should be mentioned that the axes of the Cartesian coordinate system in this case differ from the axes of the previous view, in the analytical part of the paper the longitudinal axis is the $\mathrm{x}$-axis, and in the numerical part the longitudinal axis is the $\mathrm{z}$-axis.

For the unrestrained C-cross section column the critical factor of buckling obtained with the "buckling" analysis in SAP2000 v14 [19] is $91.2 \mathrm{kN}$. The column was loaded with the unit force (in the centre of gravity of the cross section), which means that the critical force is $F_{k r}=91.2 \mathrm{kN}$. It can be seen on the deformed shape of the unrestrained C-cross section column that the loss of the column's stability appears under pure flexural in-plane buckling, Fig. 10.

For the laterally restrained C-cross section column, the critical factor of buckling obtained with the "buckling" analysis in SAP2000 v14 [19] is $141.6 \mathrm{kN}$. The column was loaded with the unit force (in the centre of gravity of the cross section), which means that the critical force is $F_{k r}=141.6 \mathrm{kN}$. It can be seen on the deformed shape of the laterally restrained C-cross section column that the loss of the column's stability appears under simultaneous twisting and lateral out-plane bending, Fig. 11.

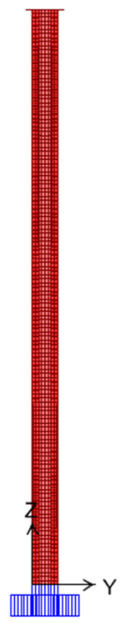

a)

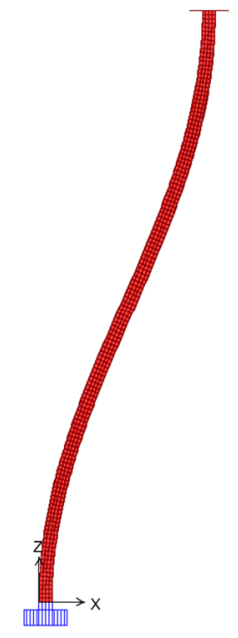

b)

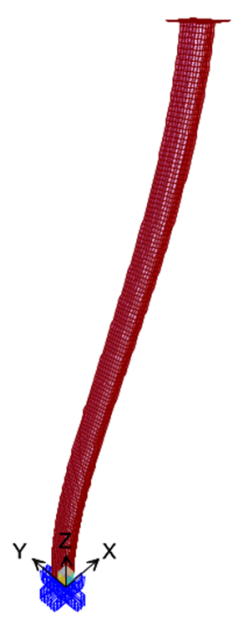

c)

Fig. 10 Deformed shape of the unrestrained C-cross section column under the action of the critical force: a) $y-z$ plane, b) x-z plane, c) 3D view 


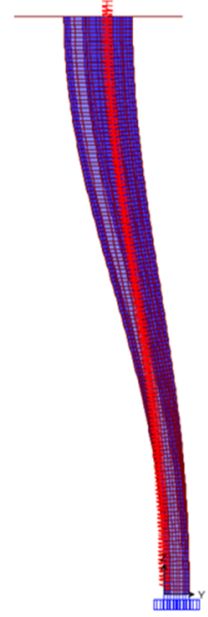

a)

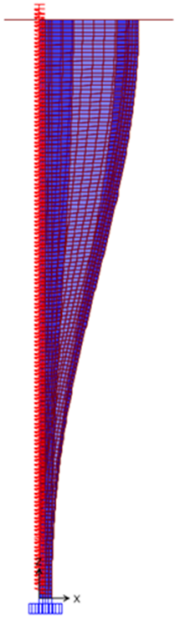

b)

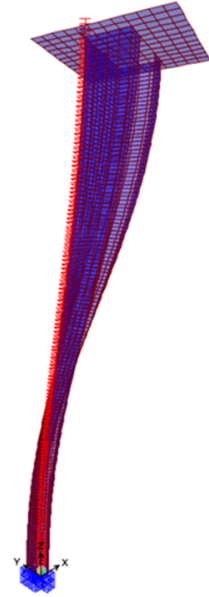

c)

Fig. 11 Deformed shape of the laterally restrained C-cross section column under the action of the critical force: a) y-z plane, b) x-z plane, c) 3D view

\section{Overview of the results of theoretical and experimental investigation}

The values of the critical forces $F_{k r}$ for the thin-walled C-cross section columns with and without lateral restraint which are analysed and compared have been obtained analytically based on the theory of thin-walled open cross section beams, numerically by using the FEM and experimentally by testing. The results are shown in Table 1 . The results of the analytical, numerical and experimental tests are matching in satisfactory agreement. For the unrestrained $\mathrm{C}$-cross section columns, as well as for the laterally restrained C-cross section columns, the agreement is within the boundaries of the relative difference of $0-5 \%$. This deviation in the results could be explained by imperfections in real elements (geometric imperfections, material inhomogeneity, residual stresses), as well as by model imperfections in the approximation of the mathematical and numerical model.

Table 1 Comparison of the critical forces

\begin{tabular}{|c|c|c|}
\hline$F_{c r}[\mathrm{kN}]$ & Unrestrained column & Laterally restrained column \\
\hline$F_{\text {exp }}$ & 90.0 & 138.0 \\
\hline$F_{\text {theor }}$ & 92.8 & 145.4 \\
\hline$F_{S A P}$ & 91.2 & 141.6 \\
\hline
\end{tabular}

In Table 2. the values of the critical forces of the tested C-cross sections are shown, giving the comparison between the increase in the critical forces of laterally restrained columns and in the critical forces of unrestrained columns. A relative increase in the critical forces is notable (53-57\%) in the experimental investigation, the analytical analysis, and the numerical analysis.

Table 2 Relative difference between the critical forces of unrestrained and laterally restrained columns

\begin{tabular}{|c|c|c|c|}
\cline { 2 - 4 } \multicolumn{1}{c|}{} & $\begin{array}{c}\text { Experimental } \\
\text { investigation }\end{array}$ & $\begin{array}{c}\text { Theoretical } \\
\text { investigation }\end{array}$ & $\begin{array}{c}\text { Numerical } \\
\text { investigation }\end{array}$ \\
\hline Unrestrained column, $F_{U C}[\mathrm{kN}]$ & 90.0 & 92.8 & 91.2 \\
\hline Laterally restrained column, $F_{L R C}[\mathrm{kN}]$ & 138.0 & 145.4 & 141.6 \\
\hline$\left(F_{L R C}-F_{U C}\right) / F_{U C} \cdot 100 \%$ & 53.33 & 56.68 & 55.26 \\
\hline
\end{tabular}


Structural Stability of Thin-Walled C-cross Section

Column Subjected to Axial Force

We can notice also that all the resulting forms of loss of stability are in agreement. All unrestrained columns lose stability in the form of pure flexural in-plane buckling in the plane with the least flexural stiffness, while all laterally restrained columns lose stability in the form of simultaneous twisting and lateral out-plane bending. In all cases, a global loss of stability occurs, because the local loss of stability was intentionally avoided by selecting an appropriate cross section of the test models, using the corresponding cross-sectional dimensions and edge fold stiffeners of the flanges. It should be kept in mind that the local failure is generally a common occurrence in thin-walled open cross section beams and columns.

\section{Conclusion}

The results of the analytical, numerical and experimental tests are in satisfactory agreement, within the boundaries of the relative difference of $0-5 \%$. The resulting forms of loss of stability are also in agreement. In all investigations, the critical force observed in the laterally restrained models is approximately equal and substantially higher than the critical force in unrestrained models, which indicates a considerable influence of the trapezoidal steel sheeting as lateral restraint on the stability of thin-walled columns subjected to axial forces. Relative increase in the critical forces in the experimental tests, in the numerical investigation, and in the analytical analysis is $53-57 \%$, and a significant impact of the lateral restraint in the form of the profiled trapezoidal steel sheeting on the stability of C-cross section columns subjected to axial forces has been proven.

The existing investigations into laterally restrained thin-walled open section members are limited to beams subjected to gravity or lifting load, and such kind of load is also included in the standards (Eurocode 3, part EN 1993-1-3) [17]. The case of laterally restrained columns subjected to axial forces has been insufficiently considered both in scientific research and the existing regulations. While the results of the paper show a significant degree of influence of lateral restraint to the stability of thin-walled open section members subjected to axial forces, consideration of the possibility of optimizing the use of thin-walled open cross section in practice by means of material savings and weight reduction of girders is proposed, which could be achieved by upgrading the existing regulations. The optimization of the use of thinwalled open cross section columns, either by updating the existing regulations or by a theoretical consideration of different positions or types of lateral restraining, can contribute to future savings in material and to weight reduction in thin-walled members while retaining the essential features of the product, both in the field of civil engineering and in the field of mechanical engineering.

The conclusions reached in this study can be used as guidelines for further research, but if a more specific analysis regarding the upgrade of the existing regulations is to be carried out, various models with different parameters (cross-sectional shape, boundary conditions, load, cross-sectional dimensions, length of model, the mechanical properties of materials, different lateral restraining etc.) should be tested.

\section{REFERENCES}

[1] D. Skejić, R. Ćosić: Proračun čeličnih tankostijenih nosača prema EN 1993-1-3, Elektronički časopis Građevinskog fakulteta Osijek, 4, 2012, 46-61

[2] D. Šimić: The Theory of Thin-Walled Beams with Open Cross Section, Faculty of civil engineering, University of Zagreb, Manualia Universitatis studiorum Zagrabiensis, Zagreb, Croatia, 2008.

[3] Mališ, T.: Stability analysis of laterally restrained thin-walled open cross-section beams, doctoral thesis, Faculty of civil engineering, University of Zagreb, Zagreb, Croatia, 2016.

[4] D. Dubina, V. Ungureanu, R. Landolfo: Design of Cold-formed Steel Structures - 1st Edition, ECCS European Convention for Constructional Steelwork, 2012. https://doi.org/10.1002/9783433602256 
[5] J. Rondal, D. Dubina: Light Gauge Metal Structures - recent advances, CISM, Udine, Italy: SpringerWienNewYork, 2005.

[6] C. H. Yoo, S. C. Lee: Stability of Structures, Principles and Applications, Burlington, USA: Elsevier (Butterworth-Heinemann), 2011.

[7] A. Foster: Stability and design of steel beams in the strain-hardening range - $\mathrm{PhD}$ thesis, London: Imperial College of Science, Technology and Medicine, 2013.

[8] D.. Dubina: Design of steel buildings with the Eurocodes, with worked examples,Cold - formed Steel Design, workshop, European Convention for Constructional Steelwork, Brussels, Belgium, 16-17 October 2014.

[9] J. Zaras, K. Kowal-Michalska, J. Rhodes: Thin-Walled Structures - Advances and Developments, 1st Edition, Kidlington, Oxford, Elsevier Science Ltd, 2001.

[10] C. Ren: Structural behavior of cold-formed steel purlin-sheeting systems under uplift loading - PhD thesis, Birmingham, UK: College of Engineering and Physical Sciences, University of Birmingham, 2012.

[11] L. Li: Lateral - torsional buckling of cold - formed zed - purlins partial - laterally restrained by metal sheeting, Elsevier, Thin - Walled Structures, 42, 995-1011, 2004. https://doi.org/10.1016/j.tws.2004.03.005

[12] J. Pavola, S. Salonen: Flexural-torsional stability of thin-walled columns, Journal of Engineering Mechanics, 118, 12, 2384-2400., 1992. https://doi.org/10.1061/(ASCE)0733-9399(1992)118:12(2384)

[13] D. Šimić Penava, A. Radić, T. Ilijaš: Elastic stability analysis of thin-walled C- and Z- section beams without lateral restraints, TRANSACTIONS OF FAMENA, XXXVIII, 2, 41-52, 2014.

[14] D. Simić: The impact of lateral restraint on the stability of the thin-walled Z-section beam, 27th Symposium on Advances in Experimental Mechanics, Institute of Machines Design and Operation, Wroclaw, 2010, 191-192.

[15] Z. Ye, R. J. Kettle, L. Li, B. W. Schafer: Buckling behavior of cold-formed zed-purlins partially restrained by steel sheeting, Elsevier, Thin - Walled Structures , 40, 853-864, 2002. https://doi.org/10.1016/S0263-8231(02)00029-0

[16] C. Basaglia, D. Camotim, R. Gonçalves, A. Graça: GBT-based assessment of the buckling behaviour of cold-formed steel purlins restrained by sheeting, Thin-Walled Structures 72, Elsevier Ltd., 2013., 217229.

[17] Eurocode 3, Desing of Steel Structures-Part EN 1993-1-3:2006+AC:2009: General Rules-Supplementary Rules for Cold Formed Thin Gange Members and Sheeting, European Committee for Standardization

[18] D. Šimić Penava, D. Damjanović, T. Ilijaš: The impact analysis of lateral restraint on the state of stress and strain in the thin-walled Z-section beam, TRANSACTIONS OF FAMENA, XXXIX, 4, 1-14, 2015.

[19] Sap 2000 Analysis Reference Manual, Computers and Structures, Inc., Berkeley, California, 2002.
Submitted: $\quad 21.8 .2016$
Accepted: $\quad 21.11 .2016$

\author{
Tanja Mališ \\ Diana Šimić Penava* \\ University of Zagreb, Faculty of Civil \\ Engineering \\ Kačićeva 26, Zagreb, Croatia \\ *corresponding author, e-mail: \\ dianas@grad.hr
}

